\title{
DO NORMAL AO CONSUMIDOR: CONCEITO DE DOENÇA E MEDICAMENTO NA CONTEMPORANEIDADE
}

Paulo Vaz

Escola de Comunicação da UFRJ, Rio de Janeiro, RJ, Brasil.

Professor

da Escola de Comunicação da UFRJ.
RESUMO: A relação entre medicamento e doença cada vez mais se assemelha ao nexo entre uma mercadoria e seu mercado. Este artigo indica as transformações no conceito moderno de doença que tornaram possível "vender" determinada doença. Um elemento crucial da subjetividade contemporânea é o desejo de se conceber como doente a requerer um medicamento para ter uma vida longa e prazerosa. Assim, a determinação dessa mudança conceitual é um elemento adicional na avaliação das diferenças entre a subjetividade moderna e contemporânea.

Palavras-chave: Subjetividade, modernidade, doença, medicamento, marketing.

ABSTRACT: From normality to consumption: the concept of diseases and drugs in contemporary society. The relationship between drugs and diseases increasingly resembles the connection between a commodity and its market. This article discusses the changes in the modern concept of disease that stimulates the marketing of diseases. A crucial element of contemporary subjectivity is the desire to be regarded as a patient in need of a drug in order to have a long and pleasant life. Thus, the determination of this conceptual change is decisive to conceive the differences between modern and contemporary subjectivity.

Keywords: Subjectivity, modernity, disease, drug, marketing.

DOI - http://dx.doi.org/10.1590/S1516-14982015000100005

\footnotetext{
* O autor agradece ao CNPq o apoio ao projeto "Risco, portador e vítima virtual".
} 


\section{HOJE HÁ TANTA LOUCURA...}

Um modo de estimar as diferenças entre a subjetividade moderna e a contemporânea é a surpreendente incidência, hoje, de doenças mentais. A Organização Mundial de Saúde (OMS) vem recentemente reiterando que um quarto dos indivíduos do planeta sofre de algum transtorno mental a cada ano (EHRENBERG, 2004).

Embora os números não sejam estritamente comparáveis, pois nem todos os considerados loucos por aquela sociedade estavam internados, é significativo que, em 1800, na Inglaterra, havia dez mil pessoas em asilos, o que equivalia a cerca de 0,1\% da população. Em 1900, o número de internados chegou a cem mil (PORTER, 2002). Porém, como a população inglesa também cresceu nesses cem anos, o percentual de internados ainda seria inferior a 1\%. E provavelmente “os outros 99\%”, tanto em 1800 quanto em 1900, ficariam indignados se fossem classificados como doentes mentais.

Na concepção atual de doença mental, que multiplica as entidades diagnósticas, é comum que um mesmo doente tenha mais de um transtorno ao longo de sua vida, como no caso do deprimido que se torna um drogado. Apesar da sobreposição, com o passar dos anos, novos indivíduos são incluídos no conjunto daqueles que passaram por alguma doença mental. Assim, é provável que as estimativas atuais ou as de um futuro próximo apontem que a prevalência de ao menos um transtorno ao longo da vida será maior do que 50\%. Ser diagnosticado e tratado por um transtorno mental será, portanto, um evento que ocorrerá à maioria dos indivíduos.

Esse crescimento impressionante se repete se o olhar passa do agregado a doenças específicas. O transtorno obsessivo-compulsivo era tido como extremamente raro na década de 1970; estimava-se que o percentual de pessoas que em algum momento de suas vidas experimentou a doença seria de 0,05\%. Um indivíduo tinha a chance de encontrar algum obsessivo-compulsivo a cada duas mil pessoas que conhecia. Hoje, o percentual aceito está entre 2 a 3\%, embora alguns estudos sugiram 10\% como a estimativa correta (DAVIS, 2010). Um aumento vertiginoso também teria ocorrido com a depressão. Sua prevalência em meados do século XX era de 0,005\%; hoje, porém, estima-se que a depressão afeta cerca de $15 \%$ da população mundial, e que uma em cada quatro mulheres passará por um episódio depressivo ao longo de sua vida (HEALY, 1997).

Para entidades clínicas como o transtorno obsessivo-compulsivo e a depressão, é possível recuar e encontrar no passado recente doenças cujos quadros sintomáticos guardam semelhanças com os atuais. Todavia, há transtornos que só foram conceituados na década de 1980, com o surgimento do DSM-III e que, apesar de recentes, apresentam hoje uma incidência significativa, como fobia social, 
estresse pós-traumático e déficit de atenção e hiperatividade (respectivamente, 6,8\%, 3,5\% e 4,1\%, cf. Kessler et al., 2005).

Embora recém-criadas, essas doenças tiveram seus critérios diagnósticos mudados nos vinte anos que decorreram entre o surgimento do DSM-III e a publicação do DSM-IV-TR, em 2000. De início, o estresse pós-traumático, doença causada por um evento, atingiria, sobretudo, sobreviventes do holocausto, vítimas de atentados terroristas, soldados obrigados a participar de guerras injustas e bárbaras, mulheres violentadas, rebeldes torturados por estados ditatoriais ou indivíduos que enfrentaram acidentes ou catástrofes naturais. O estresse pós-traumático distinguia quem passara por eventos que se presume causar sintomas em praticamente todo mundo, mas que não fazem — ou não deveriam fazer - parte do cotidiano da maior parte das pessoas. Num movimento que pode ser conceituado como extensão a todos do direito de ser vítima, a mudança maior de critério no DSM-IV foi a ênfase na reação subjetiva de medo intenso, desamparo e horror, o que permitiu classificar como acontecimento potencialmente traumatizante eventos que antes estavam incluídos no rol das experiências normais dos indivíduos, como ver um morto ou saber da morte inesperada de um conhecido.

Para a fobia social, o critério atual requer apenas que o indivíduo experimente um medo persistente de uma ou mais situações em que seria exposto a um possível escrutínio pelos outros, e nas quais imagina que pode agir de um modo considerado humilhante. Não é mais necessário, como no DSM-III, que o indivíduo persistentemente evite essas situações (LANE, 2007). Pela mudança conceitual, não surpreende que a fobia social seja o transtorno de maior incidência hoje; afinal, quem nunca temeu agir de modo embaraçoso ou, para incluir os outros transtornos mencionados, quem não recebeu inesperadamente a notícia de que um conhecido morreu, ou quem nunca esteve tão imerso em um jogo que não conseguiu esperar por sua vez de jogar?

A questão posta por essa surpreendente mudança histórica no número de indivíduos afetados por problemas de saúde mental não é a de saber se realmente o número de doentes é hoje inflado ou, ao contrário, se o conhecimento médico anterior, por sua insuficiência, sistematicamente subestimava o sofrimento causado por doenças. Estamos diante de diferentes conceitos de doença, cada um arregimentando como referente distintos comportamentos humanos. Então, o que interessa saber é por que a maior parte de nossos contemporâneos não se espanta com a nossa presumida prevalência de doenças mentais; ao contrário, apenas se preocupa com esse "grave problema” de saúde pública e com a possibilidade de estar doente sem o saber, pois acredita na racionalidade do enunciado e confia nas instituições que afirmam sua existência. 
De acordo com uma narrativa moderna crítica à psiquiatria — narrativa que mantém laços relativamente estreitos com argumentos propostos por Nietzsche, Goffman e Foucault — , toda sociedade qualifica alguns indivíduos como loucos, pois essa prática é modo de marcar alguns como diferentes, desviantes ou perigosos. A narrativa continua, dispondo-se agora a explicar qual a função da classificação para os classificadores, que, implicitamente, classificam-se como diferentes daqueles que eles julgaram como loucos, desviantes, perigosos... A função da invenção desses indivíduos que corporificam e concentram uma série de atributos negativos é criar e reforçar o valor da identidade de todos aqueles que se atribuem positividade por negação da negatividade que inventaram: são bons por que são diferentes daqueles que classificaram como ruins.

Pela explosão ocorrida na prevalência das doenças mentais, podemos destacar um elemento crucial dessa narrativa crítica que era naturalizado, tomado como evidente - o "alguns indivíduos". Presumia-se que poucos seriam marcados como loucos, pois o sentido da classificação era regular o comportamento da maioria pelo temor, em todos implantado, de ser anormal e recompensar sua ascese com a superioridade moral sobre os classificados como doentes. Marcar o desviante como louco teria a função de exemplaridade, pois ele condensaria em seu ser tanto o desvio quanto a punição, tanto o comportamento errático quanto o sofrimento, a desvalorização social e a limitação da liberdade. Essa função de alertar a muitos para andar na linha quando estão na proximidade do descaminho não tem sentido e efetividade se os classificados como doentes tornam-se a maioria.

Quando a antipsiquiatria, nas décadas de 1960 e 1970, lutava pela abertura dos asilos, pensava-se que a moralidade social tornava louco quem não o era: o número de "falsos positivos", isto é, de pessoas consideradas doentes sem o ser, seria gigantesco. Uma concepção de normalidade alargada reduziria então o número de pessoas consideradas doentes mentais. Como propunha a frase de Dostoievsky escolhida por Foucault como uma das epígrafes de seu livro História da loucura, "não é por prender seu vizinho que alguém se convencerá de sua sanidade" (FOUCAULT, 2006a, p.1). Uma concepção diferente de sanidade, mais tolerante, menos temerosa e "defendida”, possibilitaria não trancafiar o vizinho diferente.

O movimento antipsiquiátrico foi vitorioso e as portas dos asilos foram abertas; ironicamente, como vimos pelas estatísticas sobre prevalência de doenças mentais, o resultado foi o inverso do que se esperava. De fato, se um psiquiatra na década de 1960, com imensa presciência sobre a evolução da psiquiatria nos últimos 50 anos, alertasse seus colegas e intelectuais de que o problema com o conceito de doença mental não estava na produção de falsos positivos, mas na produção de "falsos negativos", isto é, de um contingente majoritário de indivíduos a sofrer sem diagnóstico e tratamento, seus interlocutores provavelmente 
duvidariam ou da sanidade do psiquiatra presciente, ou do modo como os homens do futuro, isto é, nós, operamos a prática social de divisão entre loucos e sãos.

Como é logicamente contraditório supor uma sociedade onde os rotulados como desviantes sejam a maioria, pois então a regra efetiva seriam os desvios (que deixariam, portanto, de ser desvio, no sentido lógico), a espantosa prevalência das doenças mentais indica de imediato uma mudança decisiva no conceito: o diagnóstico de doenças mentais parece ter afrouxado seu vínculo com a infração de regras, substituindo-o pelos nexos com a sensação de bem-estar. Ou ainda, se o conceito de doença mental presume que só há doença quando há desvio em relação a uma expectativa social, na Modernidade, essa expectativa estava ancorada na regularidade do comportamento; já na atualidade, a expectativa socialmente induzida é a de ser feliz como se deve; portanto, sofrer, não ser tão feliz como se tem direito, é desviar, é ter um problema de saúde mental. Daí a relevância atual de doenças como depressão, fobia social, estresse pós-traumático, ansiedade generalizada, etc.

\section{CIGARRO OU REMÉDIO}

Que narrativa sobre a cultura contemporânea é capaz de dar conta desse impressionante aumento da prevalência de doenças mentais? Qualquer resposta precisa estabelecer um nexo entre o aumento desta prevalência e mudanças nas categorias diagnósticas, nas estratégias terapêuticas predominantes, no funcionamento da economia e nos valores culturais hegemônicos. Para realçar a singularidade de uma explicação inspirada em Foucault, aqui adotada, foram construídas três narrativas, apresentadas como alternativas para sublinhar os pontos contenciosos.

A primeira narrativa apreende o aumento de pessoas com "problemas de saúde mental" como o resultado do progresso do conhecimento. O aumento na prevalência e na incidência resultaria da mera mudança de diagnóstico. De modo abstrato, essa narrativa supõe a continuidade do objeto e a variação da percepção, mais precisamente, a independência do objeto em relação ao modo como é pensado, com o termo "descoberta” — e não “invenção” ou "produção" ou "construção” — - sendo a metáfora privilegiada na descrição da relação entre mudança de classificação e objeto classificado. Apesar do que os homens de outrora pensaram, a tuberculose é causada pelo bacilo de Koch e a Terra gira em torno do sol.

Tomando a depressão como exemplo, o DSM-IV-TR afirma que as taxas de prevalência não teriam relação com etnia, educação ou status afetivo; projetando o que essa independência sugere para a diferença cultural e histórica, suporíamos que a prevalência de deprimidos em qualquer cultura é constante, variando apenas 
a percepção e o modo de tratá-los. Por estar baseada na ideia de progresso, essa narrativa propõe ainda que a forma atual de classificação da depressão é a que melhor ordena seus sintomas, descobre suas causas, estima suas consequências e dispõe de meios efetivos de intervenção para alterar seu desastroso curso, que se inicia na tristeza comum e pode terminar no suicídio.

Ao hierarquizar as classificações, a narrativa supõe que nossa cultura é a única a não ser afetada por crenças e valores que distorcem a percepção do objeto em seu comportamento legal. Através do método científico, os cientistas conseguem fazer o que os leigos de nossa cultura e os indivíduos de outras culturas são incapazes, a saber: destacar-se de preconceitos. O método afasta o véu de crenças e valores que distorce a percepção.

A segunda forma de narrativa proporia que o aumento da incidência e da prevalência não resulta de mudanças na percepção; houve a produção social de deprimidos como objetos no mundo. Durkheim abriu o caminho com seus estudos associando a anomia ao suicídio. Na sua descendência imediata, teríamos a explicação do crime proposta por Merton em meados do século XX. Haveria um estado de descontentamento provocado pela forma estrutural da sociedade que podia conduzir um indivíduo a cometer crimes. A sociedade norte-americana colocava como ideal o sucesso econômico, mas nem todos os indivíduos tinham uma chance razoável de serem bem-sucedidos. Para certos setores da população, as chances de ascensão social por meios ilegais eram bem maiores do que por meios legais (MERTON, 1996). O desvio de comportamento e o sofrimento que provoca têm como causas a ordenação da sociedade. Mais abstratamente, o quanto se sofre e do que se sofre - por exemplo, a quantidade de doentes mentais e as formas da doença mental — dependem da estrutura e dos valores de uma dada sociedade.

Esse tipo de narrativa proporia que cada sociedade coloca exigências psíquicas singulares a seus membros, com indivíduos de culturas diferentes expressando modos distintos de fracassar em atender a essas exigências. A incidência fabulosa de fobia social seria explicada não apenas pelos critérios elásticos de inclusão no conceito, mas também porque a nossa é uma cultura das celebridades televisivas instantâneas (ELLIOT, 2003). E se o atributo maior a destacá-las do comum dos mortais é a ausência de timidez, se o ideal é ser tão desembaraçado quanto os participantes de reality shows, que expõem, sem pudor, para milhões, tanto seus corpos, quanto suas vidas privadas, poucos serão tão destemidos em relação ao escrutínio alheio e muitos serão os que se concebem como estando aquém desse ideal. Um raciocínio análogo pode ser usado para explicar o aumento da depressão, pois a felicidade, como sabemos, é um alvo particularmente elusivo e os meios de comunicação apresentam o tempo todo indivíduos que parecem ser mais felizes do que nós, comuns 
mortais. Para a incidência dos transtornos alimentares, teríamos a magreza do mundo da moda como ideal inatingível a provocar problemas psíquicos em adolescentes.

Embora esse tipo de explicação indique uma variação histórica da subjetividade a partir da mudança moral expressa no surgimento de novos ideais, ele não problematiza as relações entre o que se pensa do objeto e o que o objeto é. Nesse tipo de narrativa, objetos de conhecimento como "depressão" ou "fobia social" ou "transtorno obsessivo-compulsivo" surgem e se transformam devido à conformação do contexto, mas essa emergência e mudança não dependem do que se pensa deles. Essas explicações, portanto, não investigam o lugar e o desejo daqueles que percebem a loucura, seja a do outro, seja a própria. A ambiguidade entre cuidar e curar, de um lado, e vigiar, corrigir e melhorar, de outro, não é motivo de inquietação.

Por não problematizar a “percepção”, não há a mediação entre a mudança moral e o que os homens pensam do sofrimento e das diferenças de comportamento e modo de ser. As novas doenças são o correlato imediato dos novos valores, que aparecem como ideais a pressionar os indivíduos (felicidade, celebridade, magreza, etc.) A única forma de explicar a ação da mudança moral articula os valores ao funcionamento psíquico. Muito facilmente, portanto, este tipo de análise tende a denunciar a sociedade por fazer o indivíduo sofrer.

As diferenças entre a narrativa de tipo Durkheimiana e a de tipo Foucaultiana podem ser antecipadas por meio da analogia entre a indústria do tabaco e a farmacêutica na causação de doenças. Com a venda de cigarros, a primeira produziu concretamente um grande número de pessoas com câncer de pulmão. Já a indústria farmacêutica, para vender seus produtos, precisa persuadir os indivíduos de que eles podem estar doentes, precisa incitá-los a se conceberem e a serem concebidos como frágeis, necessitando de ajuda. O decisivo não é a produção imediata de sofrimento, como no caso da indústria do tabaco, mas, sim, aquela mediada pelo sentido dado ao sofrimento.

A explicação de matriz Foucaultiana articula o aumento na incidência e prevalência, em primeiro lugar, às mudanças econômicas e sociais, mas na medida em que estas implicam uma determinada atitude diante do sofrimento. Em segundo lugar, analisam como essa atitude se traduz em novas categorias de diagnóstico e intervenção. Aqui, a nova atitude diante do sofrimento será explorada pelas mudanças no conceito de doença ocorridas desde meados do século XX. Por essa razão, a dimensão do poder enfatiza o interesse econômico da indústria farmacêutica — mais precisamente, o fato de que cada vez mais ela concebe a relação entre doença e medicamento na forma do nexo entre mercado e mercadoria. Para vender seus medicamentos, ela necessita vender uma dada doença; vender a doença, porém, significa fazer com que o indivíduo deseje 
se conceber como doente, como membro da classe de sofredores à espera de diagnóstico e tratamento. Para cada nova substância fabricada, portanto, haverá o esforço de produzir doentes em potencial, que são, de fato, consumidores de tecnologia.

Concretamente, a mudança no conceito de doença tem como base a transformação nos componentes que flexibiliza a demanda de medicamentos, isto é, que permite tornar variável o número de indivíduos que se concebem e são concebidos como doentes. Esses componentes do conceito de doença são: 1) a dissociação da unidade moderna entre sintoma e contrapartida anatômica para as doenças orgânicas; 2) a normatividade do bem-estar em substituição à centralidade do desvio; 3) a criação de critérios separando o doentio que se parecem com o que anteriormente era considerada parte necessária da vida humana ou diferença individual irrelevante para a existência de patologia.

Essa articulação entre poder, saber, economia e moralidade poderia ter sido exposta mais diretamente a partir da conceituação da sociedade de controle, proposta por Deleuze. A sociedade disciplinar estava associada ao capitalismo de produção, que dependia da constituição de corpos dóceis, produtivos economicamente e submissos politicamente. Como o louco era parente do perverso sexual e vizinho do delinquente (FOUCAULT, 1984), o duplo do psiquiatra, isto é, aquele que aparentemente está o mais distante, que é colocado como seu oposto, mas que pode ser, de fato, sua verdadeira face, era o policial. Cuidar daquele que sofre por meio da internação em asilos parecia ser mero pretexto para fazer o trabalho de policial sob a justificativa da compaixão médica: afastar os indesejáveis e perturbadores do convívio com os normais, mas para o bem deles, para se curarem de suas doenças.

Já a sociedade de controle está associada ao capitalismo de superprodução (DELEUZE, 1990). A produção de subjetividade tem então como objetivo maior produzir "bons consumidores”, aqueles capazes de sustentar um consumo para além da "necessidade”. O duplo do psiquiatra — e, de modo mais genérico, do médico - torna-se o vendedor, pois os doentes, cada vez mais, são constituídos como consumidores usando medicamentos quando não precisam, ou, mais exatamente, se fossem aplicados os critérios de normalidade válidos até meados do século XX, quando não seriam doentes.

Assim como a proximidade entre o psiquiatra e o policial não era fantasia de intelectual, revelando-se às vezes de forma ruidosa, como na internação de dissidentes sob pretexto de loucura na antiga União Soviética, a proximidade inquietante entre o médico e o vendedor pode emergir no espaço público. Eis um caso: em 14 de fevereiro de 2012, foi noticiada a assinatura de um acordo entre o Conselho Federal de Medicina (CFM), a Associação Médica Brasileira (AMB), a Sociedade Brasileira de Cardiologia (SBC) e a Interfarma, uma asso- 
ciação de laboratórios farmacêuticos multinacionais que operam no Brasil. ${ }^{1}$ O acordo estipulou os limites do comportamento ético das empresas no financiamento de congressos. O que sugere claramente o problema de legitimidade gerado pela proximidade entre médico e vendedor é o fato de o acordo ter sido obrigado a enunciar que a realização de congressos em navios de cruzeiro ou o pagamento de despesas de lazer pode comprometer a dimensão acadêmica do evento, a enunciar que é legítimo financiar passagem e estadia para os médicos, mas ilegítimo custear a despesa de seus familiares e convidados; por fim, no enunciado talvez mais sintomático, que a distribuição da verba de participação não pode seguir parâmetros comerciais, como o número de prescrições de um dado medicamento. Afinal, se o congresso se realizar em um navio ou em um resort de luxo, se a ida e estadia de familiares ou acompanhantes forem pagas pelo laboratório e se o critério principal de seleção for o número de receitas emitidas, como distinguir entre o convite a um médico para atualizar seus conhecimentos por participar de um evento científico e as viagens pagas por empresas como prêmio de vendedor do ano? Pior, se souber dessa promiscuidade entre os médicos e a indústria farmacêutica, um paciente pode temer que, ao prescrever um determinado tratamento, seu médico esteja pensando no financiamento de sua próxima viagem, e não em sua saúde.

Uma questão permanece. Se a estratégia de marketing básica dos laboratórios é vender uma doença, a questão posta por essa formulação é saber quais doenças podem ser vendidas. Sob outro ponto de vista, se é marca das culturas contemporâneas a imensa prevalência de doenças mentais, o que caracterizaria o conceito de doença da Modernidade de modo a que não fosse possível aumentar o número de pessoas que se consideravam doentes? E que mudanças nesse conceito moderno a Atualidade introduziu que permitiram "flexibilizar" a demanda de medicamentos? Para responder a essas questões, teremos que pensar por que hoje queremos nos conceber como doentes.

\section{SINTOMA, NORMALIDADE E FUTURO}

Foucault resume a mudança provocada pelo surgimento da medicina moderna pela diferença na questão que os médicos endereçavam a seus pacientes: ao invés de perguntarem "o que você tem?", passaram a perguntar “onde dói?”. Além de indicar a redução na autoridade do indivíduo sobre o que lhe acontece, a diferença de questão implica a objetivação do sofrimento na espacialidade do corpo (FOUCAULT, 2006b). A objetivação é decisiva; a diferença entre a medicina

\footnotetext{
${ }^{1}$ Disponível em http://portal.cfm.org.br/images/stories/pdf/protocolo_cfm_amb_sbc_interfarma.pdf. Acesso em 20/10/2014.
} 
moderna e as práticas curativas que existiram antes ou em outras culturas é que se deixa de pensar a doença como desequilíbrio da relação entre o indivíduo e as forças que este acredita existir no cosmos e passa-se a supor uma contrapartida anatômica para os sofrimentos humanos.

A objetivação começou com a anatomia patológica e prosseguiu, ao longo do século XIX, em três frentes (PORTER, 2003). A primeira foi a invenção de modos de "ver" os processos patológicos operando num corpo vivo, sem esperar pela morte. Da invenção do estetoscópio até as máquinas para tomografia computadorizada e ressonância magnética, o que sustenta é a exigência de tornar visível processos patológicos no corpo. Uma segunda forma de objetivar foi a criação do conceito de homeostase, que permitiu a definição de limiares quantitativos para a existência do patológico. A diabete é o caso exemplar; para a experiência contemporânea, porém, os índices quantitativos mais importantes e lucrativos são a tensão sanguínea e o colesterol. A terceira forma de objetivação surgiu com as descobertas de Pasteur e Koch, associando uma doença a um germe (vírus ou bactéria) e a um tratamento, com o consequente desenvolvimento das vacinas, das práticas de higiene, de controle de vetores e a descoberta dos antibióticos.

A contrapartida anatômica para os sintomas definia as doenças orgânicas. As doenças mentais, por sua vez, definiam-se exatamente pelo inverso, isto é, pela ausência de contrapartida. Todo o ser de uma doença mental está no desvio em relação a uma expectativa social. As famosas curas por hipnose das paralisias histéricas por Charcot foram também modos de definir o espaço da doença mental: elas sofriam, embora nada houvesse em seus músculos ou ossos que respondesse pela imobilidade. Ainda, quando hipnotizadas, isto é, quando estava enfraquecida a consciência de si, as histéricas não exibiam nenhuma patologia; uma hipótese, portanto, para a origem da doença seria a sua consciência, mais precisamente aquilo que produz a sua consciência moral, como será depois teorizado pela psicanálise (VAZ, 1997).

Além de serem marcadas pela ausência de contrapartida anatômica, as doenças mentais, na Modernidade, deixaram de ser predominantemente percebidas no eixo opondo o delírio à razão, com a ênfase se deslocando para o eixo articulando fraqueza da vontade e ato desviante. Como o mostra o conceito de monomania, um indivíduo podia ser normal em tudo, menos no hábito que caracterizava sua loucura. Definida, portanto, pelo comportamento desviante, a doença mental também se associava, na forma da causalidade que explica o seu surgimento, aos problemas do instinto sexual, direcionado para onde não deveria e difícil de controlar, dadas as suas exigências. Em síntese, a doença mental na Modernidade se definia apenas pelos sintomas. Quem diagnosticava, porém, era o psiquiatra e a loucura se manifestava privilegiadamente no ato desviante. 
Podemos agora responder à pergunta sobre por que o conceito moderno tendia a impedir os esforços de vender doença, isto é, de ampliar o número de indivíduos que desejam se pensar como doentes. No caso das doenças orgânicas, o nexo requerido entre sintoma e contrapartida anatômica provocava uma dupla restrição. Sem sintomas, os indivíduos tendiam a não procurar médicos, tanto assim que campanhas de saúde pública e a pressão das seguradoras foram, ao longo do século XX, decisivas para naturalizar a prática da consulta anual, o que torna possível a descoberta de processos patológicos sem haver ainda sintoma. E só com sintomas, sem contrapartida anatômica, os indivíduos não tinham doença orgânica; no máximo, um problema mental. Sem sintoma, mesmo com contrapartida, não havia reconhecimento médico da doença; só com sintoma, sem contrapartida, não havia doença orgânica.

No caso das doenças mentais, três razões maiores limitavam a expansão dos indivíduos que se considerariam doentes: 1) faria parte constitutiva da loucura não reconhecer-se como louco; 2) ser assim classificado estigmatizava, tanto pela necessidade do desvio moral e legal para o diagnóstico, quanto pela presunção de que o desvio se originaria nas perturbações da sexualidade; 3 ) o tratamento era a entrada compulsória num asilo, o que, além de estigmatizar, atemorizava. Pela forma de diagnóstico e de tratamento, ninguém queria ser louco.

A conceituação moderna de doença — se orgânica, contrapartida anatômica para sintomas; se mental, ausência de contrapartida e manifestação no desvio moral e legal - começa a oscilar com o que se costuma chamar de transição epidemiológica, originada no próprio sucesso da medicina, especialmente o desenvolvimento de vacinas e antibióticos. A causa principal de morte deixa de ser as doenças infectocontagiosas, como sífilis e tuberculose, e torna-se as doenças crônico-degenerativas, principalmente as doenças cardiovasculares e os cânceres. Para estas, a sequência temporal "sintoma, contrapartida anatômica e intervenção” é problemática, pois ou a manifestação do sintoma tende a coincidir com a morte ou aparece quando nenhuma intervenção tem eficácia. Ou não dá tempo de intervir, ou já é tarde demais.

Para manter sua razão de ser, para continuar sendo lugar maior do esforço dos seres humanos de se manterem em vida enquanto der, a medicina ocidental moderna desenvolveu o conceito de fator de risco no estudo das doenças crônico-degenerativas. Para estas, é preciso diagnosticar antes de haver sintoma. O que se descobre não é a doença já constituída, mas o que indica a sua mais ou menos provável manifestação futura.

Como vimos, a dissociação entre sintoma e contrapartida anatômica foi o que abriu a possibilidade de "vender doença”. Para as doenças infectocontagiosas, a estratégia de atemorizar e prometer a salvação por atender a certos comportamentos só é factível em casos de epidemia. No caso da contrapartida anatômica 
de um fator de risco, isto é, do que indica a eventualidade de sintomas no futuro, é factível aumentar o número de portadores simplesmente por variar o limiar quantitativo a partir do qual se define uma anormalidade, uma probabilidade tida como inaceitável de adoecer no futuro.

Quatro doenças são exemplares desse recuo do limiar de normalidade. Desde a década de 1980, para a hipertensão, colesterol alto, diabete e osteoporose, os limiares passaram, respectivamente de 16 por 10 para 14 por 9 , de 240 para 200, de 140 para 126 e de 2,5 para 2,0. O número de pacientes, ou potenciais consumidores, aumentou de $14 \%$ para diabete até $89 \%$ para o colesterol alto (WELCH, SCHWARTZ, WOLOSHIN, 2012).

A justificativa básica é a de que o novo limite induz mais pessoas a se tratarem e, assim, reduz as chances de advento da doença. Esse argumento seria válido se o tratamento fosse sem custo algum, mesmo que apenas monetário; afinal, o aumento no número de possíveis pacientes significa um aumento enorme do número de falsos positivos, isto é, daqueles que se tratam por nada, pois ou não iriam desenvolver a doença ou a desenvolveriam de todo modo. A partir dessas mudanças de limiar, o número de falsos positivos nunca é inferior a $50 \%$. A maior parte está tentando reduzir as chances de ocorrência futura de uma doença sem que o esforço fosse necessário ou tivesse algum efeito positivo.

O limiar de normalidade se descola aqui do que é majoritário numa população e se torna o que estipula uma segurança aceitável; mais precisamente, o limiar indica que a chance de contrair uma dada doença foi reduzida a uma probabilidade pequena o suficiente para se tornar médica e socialmente aceitável. A eficácia de um tratamento medicamentoso para chegar a esse limiar, definido, sobretudo, pela esperança de não morrer, é tão marcada pela incerteza quanto o comportamento que aumenta o risco de contração da doença. O que é observado numa população não vale para o indivíduo; assim como todo mundo conhece um fumante muito idoso e um não-fumante que morreu de câncer de pulmão, chegar ao limiar estipulado como normalidade não garante a recompensa de não contrair a doença no futuro e, portanto, para muitos, tomar o remédio para se tornar normal não é necessário, ou não adianta. E até onde o limiar de normalidade pode ser reduzido? Se a intervenção tem efeito colateral, até o momento em que o efeito colateral for maior que o risco. Se não houver efeito colateral, a redução pode continuar indefinidamente, pois o movimento de recuo é ditado pela nossa esperança ilimitada de não morrer e, ao mesmo tempo, morreremos e, portanto, nunca haverá risco nulo. Mesmo que um novo limiar de normalidade apenas reduza a chance de contrair a doença de $15 \%$ para $10 \%$, quem não desejaria participar da loteria e ser um dos 5\% premiados?

As mudanças de limiar foram feitas pelo FDA, órgão norte-americano responsável pela saúde pública a partir da recomendação de uma comissão de especia- 
listas. É significativo que, em todas essas mudanças de limiar, a maior parte dos especialistas tinha laços financeiros com empresas farmacêuticas. Não é preciso supor corrupção e maquiavelismo dos médicos; basta pensar que são especialistas que se atribuem a missão de tudo fazer para evitar essas doenças, sem pensar nas consequências dessa cruzada para o lucro dos laboratórios (MONYHNAN, 2006; WELCH, SCHWARTZ, WOLOSHIN, 2012).

Para os cânceres, o esforço de encontrar a contrapartida anatômica antes do sintoma se deu pelo desenvolvimento das técnicas de imagem. O problema nesse caso é semelhante ao do limiar quantitativo do fator de risco, com o aumento do número de falsos positivos. Com o refinamento das técnicas, mais anomalias são vistas, mas maior é a dificuldade de decidir se já são ou não doença, ou mesmo signos confiáveis de sua aparição futura (WELCH, SCHWARTZ, WOLOSHIN, 2012). Quantos lagos existem na Inglaterra? Depende das técnicas de imagem e da definição. Se aumentar a resolução da imagem, por que não considerar um depósito de água com mil metros de diâmetro como um lago? E o que fazer com formações anômalas em órgãos, se a maior parte delas não se tornará sintoma e nem abreviará a vida de indivíduos? Não seria melhor tratar preventivamente, já que a intervenção seria mais eficaz do que o tratamento após o sintoma e em alguns casos essas anomalias são o começo de cânceres?

Além das que se definem pela contrapartida anatômica, mas sem sintoma atual, só indicando a probabilidade de sintomas no futuro, passa a haver também a classe de doenças orgânicas que se definem pela ausência de sintomas, mas que não são doenças mentais. Essas serão tão mais fáceis de serem vendidas quanto mais os seus sintomas estiverem próximos do que antes seria visto como normalidade ou como incômodo aquém do limiar da atenção médica (ELLIOTT, 2010b). Um exemplo é a síndrome do intestino irritável. Seu diagnóstico se dá por exclusão de contrapartida anatômica — não é vírus, bactéria ou câncer e pela presença de sintomas como diarreia ou prisão de ventre frequentes ou alternância entre estes estados. Dependendo do modo como são idealizadas a frequência e a consistência normais, esse conceito permite um número razoável de consumidores em potencial a ser explorado pela indústria.

Para alguns, o mal de Alzheimer também pode ser incluído nesse grupo, pois a sua contrapartida anatômica tende a se parecer com o processo natural de envelhecimento no cérebro. A definição funcional, sintomática, frisando as dificuldades cognitivas também apresenta a dificuldade de separar a doença do que seria resultado do processo natural de envelhecimento (idem). Por esta postura ativista, que se propõe a encontrar medicamentos que aumentem a autonomia e, assim, o bem-estar de idosos, será possível aumentar o número de indivíduos que são diagnosticados como doentes; no limite, todo idoso poderá ser medicado. 
O mal de Alzheimer indicou, implicitamente, uma quarta possibilidade de vender doença. Trata-se da construção de sintomas cuja distinção com processos antes vistos como naturais é muito pouco clara. O exemplo maior é a "disfunção erétil”, também passível de um trabalho de redefinição do sintoma que torna todo indivíduo acima da adolescência como um doente em potencial. Pode-se pensar que, nesses casos, o critério de normalidade não tem mais como referência um processo natural e, sim, o bem-estar do indivíduo. Em suma, as modificações no conceito de doença orgânica que permitem aumentar a demanda são a dissociação entre sintoma e contrapartida e a definição como sintoma de processos orgânicos pouco discerníveis do que antes era considerado, senão saudável, ao menos parte dos processos naturais articulando vida e morte. Nos dois casos, o socialmente definido como normal se idealiza e se torna não um dado, mas o resultado de um cuidado que contém o uso de medicamentos.

A normatividade do bem-estar, isto é, de uma sensação subjetiva, será também a alavanca a impulsionar o surgimento de novas doenças mentais e, assim, de novos consumidores. Ou melhor, essa normatividade passa a exercer todo o seu poder quando acompanhada de duas mudanças no conceito de doença mental.

A primeira mudança é a possibilidade de contrapartida anatômica, não como forma de fazer dos "transtornos" doenças orgânicas, mas, sim, como mecanismo para sustentar a superioridade de uma relação técnica de si a si. Que um transtorno resulte de um desequilíbrio químico, isso só indica a possibilidade de um tratamento por remédios. Pois o que define qualquer transtorno não é mais sua causa, mas, sim, seus sintomas.

A segunda mudança é a perda de relevância do ato desviante na manifestação de doença mental. Quando a referência de grande parte das doenças mentais é o bem-estar, o desvio de uma normatividade não é mais o ato imoral ou criminoso e, sim, o sofrimento nas suas inumeráveis formas. Dito de outro modo, na Modernidade, a expectativa social enfatizava o comportamento disciplinado e a perturbação mental que atravancava a sua existência. Hoje, a expectativa social a partir da qual se detecta desvio frisa o bem-estar que deveria ser experimentado por cada um. Desde então, apoiando-se na incerteza sobre a normalidade do estado mental de cada um — mais precisamente, na incerteza sobre a suficiência do bem-estar e da performance social que presumidamente o permite, incerteza sempre possível de ser alimentada pela impossibilidade de acesso direto à mente dos outros - , e prometendo incessantemente a todos nós que é possível viver melhor, as empresas farmacêuticas puderam aumentar de modo espetacular o número de consumidores de medicamentos por terem favorecido o aumento do número de pessoas que se consideram e são consideradas doentes.

Essa venda de doença mental deve ainda retirar o estigma social associado à classificação de doença mental e de seu tratamento. Algumas matérias de revistas 
semanais brasileiras sobre doenças mentais mais parecem publicidades de medicamentos do que reportagens; nelas, costuma-se começar argumentando que uma dada doença mental é um grave problema de saúde pública, pois é desconhecida, embora de enorme prevalência, o que só não é paradoxal porque seus sintomas são muito parecidos com o que se pensava ser normal. Para reforçar a cotidianidade da doença, para desestigmatizá-la, as matérias costumam recorrer a histórias de vida e depoimentos de celebridades revelando como sofreram com a doença e conseguiram superá-la pelo uso de medicamentos.

O uso de celebridades e a ênfase na presumida naturalidade da intervenção não são apanágios das revistas semanais brasileiras; num caso já bastante estudado, no Japão, a promoção da depressão por parte da associação de laboratórios farmacêuticos multinacionais usou como slogan a sentença “a depressão é a gripe da alma”. Asseguravam, assim, imediatamente, que seu tratamento é simples e requer medicamentos; contou ainda com a sorte de ser revelado que a princesa foi diagnosticada com a doença (APPLBAUM, 2006; WATTERS, 2010).

\section{NA PROXIMIDADE DA LOUCURA}

Pensar-se na potencialidade de estar louco é habitar a distância inquietante entre o que se é e o que se pode ser. Quando a loucura se desdobrava como anormalidade, essa distância era constituída pela simultaneidade entre, de um lado, o medo que paralisa nossos impulsos desviantes e nos torna iguais a todos, e, de outro, o desejo de uma vida diferente da que se vive, uma vida para além de todo dever, recortada por prazeres estranhos e perturbadores.

Retomemos o que Foucault escreveu, em História da loucura, sobre o grande medo, no século XVIII, dos asilos onde se internavam loucos, criminosos, vagabundos e libertinos. Pela teoria do miasma, temia-se que os asilos à margem das cidades fossem a fonte de inúmeras doenças para os habitantes. Imaginaram, então, reformas arquitetônicas que tornassem os asilos ventilados, pois o mal poderia então "vegetar sem nunca se difundir", e que colocassem os desatinados em celas que fossem como jaulas, permitindo sua contenção e seu uso pedagógico. Nesse asilo reformado, imaginava um padre chamado Desmonceaux, o espetáculo dos loucos aprisionados faria com a que juventude licenciosa refletisse sobre o preço da imoralidade (FOUCAULT, 2006a, p.359).

Há uma ameaça a essa utopia de moralista: estar na distância dos desatinados também excita a imaginação e os desejos. A moral sonha em afastar esses perigos, "mas algo existe no homem que se obstina em sonhar vivê-los, ou pelo menos aproximar-se deles e libertar seus fantasmas. O horror que agora cerca as fortalezas do internamento também exerce uma atração irresistível. As pessoas sentem prazer em povoar essas noites com inacessíveis prazeres; essas 
figuras corrompidas e carcomidas tornam-se rostos de voluptuosidade" (idem, p.360). Talvez porque os desatinados, de tão devastados, nada mais devam e, assim redimidos, de tudo possam experimentar: só loucos fazem certas coisas...

Hoje, porém, por sua incidência e prevalência, a doença mental não pode mais ocupar o lugar de diferença perturbadora a partir da qual tanto se suscita o desejo, em cada um, de dela ser diferente e, assim, de ser como todo mundo, quanto se experimenta a dolorosa insistência do desejo por uma vida outra.

De fato, se a doença mental hoje se assemelha a uma gripe, como apregoam aqueles que querem lucrar com sua disseminação, o sofrimento experimentado na distância da possibilidade de loucura se reduz a ser a face negativa da esperança de uma vida melhor obtida com o consumo de um objeto técnico. Vida melhor que perde o que continha de mistério e desconhecido, reduzida que está à idealização reforçadora dos valores hegemônicos. Antes, a distância entre o que se é e o que se pode ser era ocupado por um indivíduo que se classificava como normal e imaginava o que poderia ser sua vida se agisse como os "loucos"; agora, porém, somos incitados a nos conceber como possíveis doentes apenas para imaginar que seremos, enfim, felizes graças ao uso do medicamento. Não há mais diferença entre conceber-se como louco ou como aquele a quem falta um carro, ou um sanduíche, um refrigerante, um celular, etc. Falta a cada um de nós uma felicidade à qual temos direito e que obteremos se consumirmos este ou aquele produto.

Nos Estados Unidos, é permitida a propaganda direta ao consumidor de medicamentos com venda restrita. Encontraremos nessas peças publicitárias estratégias retóricas que aparecem nas reportagens, como a descrição vaga dos sintomas para permitir que a audiência atribua o sentido de doença mental aos seus males existenciais: para a ansiedade generalizada, não dormir porque se preocupa com amigos e a família ou ser alguém que, quando está em casa, preocupa-se com o que acontece no trabalho e, quando no trabalho, com o que acontece em casa; para a depressão, sentir-se solitário, não dormir direito ou lembrar-se, entristecido, de que já se sentiu feliz; para a fobia social, temer intensamente situações sociais nas quais encontraremos pessoas que não nos são familiares e, pela possibilidade de observação reprovadora, ter um desempenho aquém do que desejamos.

Essas peças repetem a tradicional estrutura “antes e depois", típica de propagandas de produtos para o emagrecimento: a foto do obeso seguida de sua imagem já atleta. Como a lei requer que os laboratórios alertem sobre efeitos colaterais dos medicamentos, a peça tipicamente inicia com a descrição por depoimento dos sintomas; o elemento de transição é a explicação de que os sintomas podem constituir uma doença, mas que existe tratamento; no final, aparecem imagens dos indivíduos agora felizes graças ao uso do remédio, 
enquanto uma voz enuncia seus inúmeros possíveis danos à saúde. O interessante é que as imagens de felicidade são as mesmas que aparecem em diversos outros comerciais: casais se abraçando, pais brincando com seus filhos, amigos sorrindo a passear pelo campo, pessoas eficazes e felizes no trabalho, etc.

O indivíduo se concebe como possível louco, mas na distância do já-curado, mais precisamente, do normal idealizado: o mal-estar que experimenta, se doença, tem remédio, literalmente. E a felicidade que se deseja é aquela ansiada por qualquer consumidor, sem nenhum questionamento, sem nenhuma alteridade em relação ao que é incessantemente apregoado por nossa cultura. Do mesmo modo, a possibilidade de questionamento contida na antecipação da morte é frequentemente evitada pela esperança de, ainda uma vez, adiar a morte por meio do uso de remédios e da adoção de "hábitos saudáveis". Sob a perspectiva da passagem do normal ao consumidor, não espanta que tantos indivíduos se identifiquem como doentes mentais ou acreditem ter chance de morrer - e que essa proximidade com a loucura e a morte não abra o questionamento de si e do mundo.

Recebido em 30/1/2015. Aprovado em 20/2/2015.

\section{REFERÊNCIAS}

APPLBAUM, K. (2006) "Educating for global mental health: the adoption of SSRIs in Japan”, in PETRYNA, A. LAKOFF, A. e KLEINMAN, A. (Orgs.) Global pharmaceuticals: ethics, markets, practices. Durham: Duke University Press.

DAVIS, L. J. (2010) “Obsession: against mental health”, in METZL, J. M. e KIRKLAND, A. (Orgs.) Against health — how health became the new morality. Nova York: New York University Press.

DELEUZE, G. (1990) Pourparlers. Paris: Minuit.

EHRENBERG, A. (2004) Les changements de la relation normal-pathologique. Esprit, maio, p.133-156.

ELLIOTT, C. (2003) Better than well. Nova York: W. W. Norton \& Company. (2010a) White coat, black hat. Boston: Beacon Press.

(2010b) "Pharmaceutical propaganda", in METZL, J. M. e KIRKLAND, A. (Orgs.) Against health — how health became the new morality. Nova York: New York University Press.

FOUCAULT, M. (1984) História da sexualidade I $-A$ vontade de saber. 5ed. Rio de Janeiro: Graal.

(2006a) History of madness. Londres: Routledge.

(2006b) O nascimento da clínica. 6ed. Rio de Janeiro: Forense-

-Universitária. 
HEALY, D. (1997) The antidepressant era. Cambridge, MA: Harvard University Press.

KESSLER, R. C. et alli (2005) Prevalence, severity, and comorbidity of twelve-month DSM-IV disorders in the National Comorbidity Survey Replication (NCS-R). Archives of General Psychiatry, 62 (6), p.617-627.

LANE, C. (2007) Shyness: how a normal behavior became a sickness. New Haven: Yale University Press.

MOYNIHAN, R. e CASSELS, A. (2006) Selling sickness. Nova York: Nation Books.

MERTON, R. K. (1996) On social structure and science. Chicago: Chicago University Press.

PORTER, R. (2002) Madness - a brief history. Oxford: Oxford University Press.

. (2003) Blood and guts — a short history of medicine. Londres: Penguin Books.

VAZ, P. (1997) O inconsciente artificial. São Paulo: Unimarco.

WATTERS, E. (2010). Crazy like us: the globalization of the american psyche. Nova York: Free Press.

WELCH, H. G.; SCHWARTZ, L. M.; WOLOSHIN, S. (2012) Over-diagnosed: making people sick in the pursuit of health. Boston: Beacon Press.

Paulo Vaz

paulo.vaz@eco.ufrj.br 